\title{
ANÁLISE ECONÔMICA DA PRODUÇÃO DE MILHO DOCE IRRIGADO NO NORDESTE DO MATO GROSSO DO SUL
}

SOUZA, Epitácio José de ${ }^{1}$ CUNHA, Fernando França da ${ }^{2}$ BAIO, Simone Pereira da Silva ${ }^{3}$ MAGALHÃES, Fernando Fagner ${ }^{4}$ SILVA, Thiago Ramos da ${ }^{5}$ SANTOS, Osvaldir Feliciano dos ${ }^{6}$

RESUMO: O objetivo deste trabalho foi avaliar os custos de produção e índices de lucratividade de diferentes tratamentos envolvendo lâminas de irrigação e épocas de cultivo, na cultura do milho doce irrigado, no nordeste de Mato Grosso do Sul. O trabalho foi conduzido na área experimental da Universidade Federal de Mato Grosso do Sul, campus de Chapadão do Sul, MS. O delineamento estatístico foi o de blocos casualizados, em esquema fatorial 4 x 2 , constituído de quatro lâminas de irrigação $(50,75,100,125 \%$ da evapotranspiração da cultura - ETc) e duas épocas de cultivo (Inverno/Primavera e Verão/Outono), com quatro repetições. Foram estimados o custo operacional total, receita bruta, lucro operacional, índice de lucratividade, produtividade de equilíbrio e o preço de equilíbrio. O milho doce irrigado no nordeste de Mato Grosso do Sul apresenta maior produtividade quando cultivado na época Verão/Outono. Os itens insumos e a mão de obra são os que apresentam maior participação do custo de produção do milho doce. Todos os indicadores econômicos apontaram o milho doce irrigado como uma atividade agrícola viável.

Palavras-Chave: Zea mays var. saccharata Sturt, lâminas de irrigação, viabilidade econômica.

\section{ECONOMIC ANALYSIS OF FIELD IRRIGATED SWEET CORN IN NORTHEASTERN MATO GROSSO DO SUL, BRAZIL}

SUMMARY: The aimed of this work was to evaluate the production costs and profitability indexes of different treatments involving irrigation depths and growing seasons, in the irrigated sweet corn culture, in the northeast of Mato Grosso do Sul. The work was conducted in the experimental area from the Federal University of Mato Grosso do Sul, campus of Chapadão do Sul, MS. The statistical design was randomized blocks, in a 4 x 2 factorial scheme, consisting of four irrigation depths $(50,75,100,125 \%$ of the crop evapotranspiration - ETc) and two growing seasons (Winter / Spring and Summer / Autumn), with four repetitions. Total operating cost, gross revenue, operating profit, profitability index, equilibrium productivity and the equilibrium price were estimated. The irrigated sweet corn in the northeast of Mato Grosso do Sul, presents greater productivity, when cultivated in the Summer / Autumn season. Inputs and labor are those that have the largest share of the cost of producing sweet corn. All economic indicators pointed to irrigated sweet corn as a viable agricultural activity.

Keywords: Zea mays var. saccharata Sturt, irrigation depths, economic viability.

\footnotetext{
${ }^{1}$ ORCID Id https://orcid.org/0000-0002-3094-1237 - UniBRAS. Correspondente: epitacio_jose@ @otmail.com

${ }^{2}$ ORCID Id https://orcid.org/0000-0002-1671-1021 - Universidade Federal de Viçosa

${ }^{3}$ ORCID Id https://orcid.org/0000-0002-6925-5859 - Universidade Federal de Mato Grosso do Sul

${ }^{4}$ ORCID Id https://orcid.org/0000-0001-5168-0446 - Universidade Federal de Mato Grosso do Sul

${ }^{5}$ ORCID Id https://orcid.org/0000-0002-1848-3464 - Universidade Federal de Mato Grosso do Sul

${ }^{6}$ ORCID Id https://orcid.org/0000-0002-9322-6038 - Universidade Estadual Paulista "Júlio de Mesquita Filho"
} 


\section{INTRODUÇÃO}

O Brasil se destaca mundialmente como um dos maiores produtores de milho comum, fato que possibilita o País ter também um grande potencial para a produção de milho doce (Zea mays var. saccharata Sturt) (FERREIRA et al., 2011; SOUZA et al., 2016; SANTOS et al., 2020). A diferença básica do milho doce para o milho comum está relacionada a uma mutação genética que bloqueia a conversão de açúcares em amido no endosperma, conferindo o caráter doce (ZUCARELI et al., 2012; SOUZA et al., 2016).

Segundo Lima et al. (2020), o milho doce é bastante popular em países de clima temperado, fato não observado no Brasil. Para que esta cultura possa atingir um papel de maior destaque no cenário hortícola nacional, existe a necessidade de aperfeiçoar as técnicas de condução da cultura em condições tropicais. Dessa forma, é possível explorar o seu potencial produtivo de forma mais eficientes, assim podendo tornar mais popular entre os agricultores, com capacidade de competir com outras culturas convencionais.

É fato que a irregularidade do regime pluvial torna-se restritiva ao desenvolvimento agrícola, pois mesmo dentro de estações chuvosas, observam-se períodos de déficit hídrico. Segundo Souza et al. (2016) a suplementação de água pela irrigação permite ao produtor escalonar sua produção, assim, atendendo a demanda comercial. Segundo Zárate et al. (2009) o Estado de Mato Grosso do Sul não possuía tradição no cultivo de hortaliças, mas nos últimos anos vêm aumentando a procura de espécies alternativas e sustentáveis, em especial aquelas que podem ser cultivadas em pequenas áreas. O Estado do Mato Grosso do Sul vem apresentando desde 1960 um crescimento grande em área irrigada, sendo que de 1996 até 2015 o crescimento foi de $6 \%$ ao ano (ANA, 2015). Assim, os estudos que procuram identificar áreas com potencial para a irrigação podem contribuir para aumentar as áreas irrigadas no Estado.

Juntamente a essas tecnologias, é importante a obtenção de indicadores econômicos para fornecer subsídios para o agricultor tomar a decisão de investir em uma nova atividade. $\mathrm{O}$ cultivo de milho doce pode ser uma alternativa agronômica rentável e acreditam, que em pouco tempo, a cultura se tornará uma importante hortícola no Brasil (Araújo et al., 2006; Souza et al., 2016).

Diante do exposto, este trabalho objetivou avaliar o custo de produção e os índices de lucratividade de diferentes tratamentos envolvendo lâminas de irrigação e épocas de cultivo, na cultura do milho doce irrigado, no nordeste do Mato Grosso do Sul. 


\section{MATERIAL E MÉTODO}

O experimento foi conduzido na área experimental da Universidade Federal de Mato Grosso do Sul, campus de Chapadão do Sul-MS, localizado nas coordenadas 1846'24.38"S, $52^{\circ} 37^{\prime} 23.75^{\prime \prime O}$ e com altitude $820 \mathrm{~m}$. O clima é classificado como tropical úmido. A temperatura anual varia entre 13 e $28^{\circ} \mathrm{C}$, a precipitação pluviométrica média anual é de $1.850 \mathrm{~mm}$, com concentração de chuva no verão e seca no inverno (CASTRO et al., 2012). O solo da área é classificado como Latossolo Vermelho Amarelo Distrófico, textura argilosa Embrapa (2013).

O delineamento experimental utilizado foi em blocos casualizados, com esquema fatorial 4 x 2, com quatro repetições, sendo constituído de quatro lâminas de irrigação (50, 75, 100 e125\% da evapotranspiração de cultura-ETc) e duas épocas de plantios no Inverno/Primavera (17/08/2012) e Verão/Outono (02/03/2013), com quatro repetições por tratamento. Antes da instalação dos experimentos, o solo do local foi amostrado, para determinação dos atributos químicos, na camada de 0,0-0,20 m e os resultados das análises de fertilidade do solo foram os seguintes: $\mathrm{pH}\left(\mathrm{CaCl}_{2}\right)=5,3$ e 4,8; M.O. $\left(\mathrm{g} \mathrm{dm}^{-3}\right)=40,2$ e 35,8; CTC $\left(\mathrm{cmol}_{\mathrm{c}} \mathrm{dm}^{-3}\right)=9,4$ e 9,3; Ca $\left(\mathrm{cmol}_{\mathrm{c}} \mathrm{dm}^{-3}\right)=3,30$ e 3,40; $\mathrm{Mg}\left(\mathrm{cmol}_{\mathrm{c}} \mathrm{dm}^{-3}\right)=0,90$ e 1,$00 ; \mathrm{H}+\mathrm{Al}\left(\mathrm{cmol}_{\mathrm{c}} \mathrm{dm}^{-3}\right)=4,9$ e 4,8; $\mathrm{Al}$ $\left(\mathrm{cmol}_{\mathrm{c}} \mathrm{dm}^{-3}\right)=0,08$ e 0,$09 ; \mathrm{K}\left(\mathrm{cmol}_{\mathrm{c}} \mathrm{dm}^{-3}\right)=0,29$ e 0,$13 ; \mathrm{P}\left(\mathrm{mg} \mathrm{dm}^{-3}\right)=13,8$ e 4,8; $\mathrm{SB}(\%)=47,8$ e 48,6 para as épocas Inverno/Primavera e Verão/Outono, respectivamente.

O preparo do solo para a instalação dos experimentos constituiu-se de uma aração e uma gradagem. A correção da acidez do solo foi realizada utilizando calcário dolomítico com PRNT de 85\%, conforme recomendações de Sousa e Lobato (2004). A aplicação do calcário foi realizada após a operação de aração, em seguida foi realizada a gradagem para a sua incorporação.

Foi utilizado o milho doce hibrido Tropical Plus ${ }^{\circledR}$ espaçado por $80 \mathrm{~cm}$ entre fileiras planta, adotando uma densidade semeadura de 75.000 sementes $\mathrm{ha}^{-1}$. Com base nas características químicas. A adubação química básica no sulco de semeadura, foram de $400 \mathrm{~kg} \mathrm{ha}^{-1}$ e $600 \mathrm{~kg} \mathrm{ha}^{-1}$ da formula 06-24-14 para época Inverno/Primavera (2012) e Verão/Outono (2013) respectivamente. A adubação nitrogenada em cobertura utilizou $150 \mathrm{~kg} \mathrm{ha}^{-1}$ parcelado e distribuídos nas fases $V_{3}$ e $V_{8}$ utilizando como fonte a ureia. Já a potássica foi realizada em $V_{3}$, utilizando como fonte o cloreto de potássio na dose de $80 \mathrm{~kg} \mathrm{ha}^{-1}$.

As lâminas de irrigação foram aplicada por meio de um sistema de gotejamento, baseado na reposição por meio da evapotranspiração da cultura ETc, foi determinada a partir do Kc coeficiente de cultivo apresentado por Doorenbos \& Kassam (1979) para o milho, até a fase 3 de seu desenvolvimento e a evapotranspiração de referência ETo foi estimada pelo método de Penman-Monteith (ALLEN et al., 1998), a partir de dados diários coletados do INMET (Instituto 
Nacional de Meteorologia) rede de estação de Chapadão do Sul. Os dados de precipitação pluvial foram retirados de um pluviômetro SR instalado na área experimental.

Os tratamentos fitossanitários necessários para a implantação e condução do ensaio foram: tratamento de semente (Fipronil (12 g i.a./100 kg sementes), controle de plantas daninhas (Atrazina $2.500 \mathrm{~g}$ i.a./ha), controle insetos pragas (Lambda-Cialotrin $25 \mathrm{~g}$ i.a. ha ${ }^{-1}$ ) e controle preventivo de doenças (Azoxistrobina (60 g i.a. ha $\left.{ }^{-1}\right)+$ Ciproconazol $\left(24\right.$ g i.a. ha $\left.{ }^{-1}\right)$.

Ao atingirem a fase fenológica $\mathrm{R}_{3}$, foram realizadas a colheita das espigas. As colheitas foram realizadas nos dias 24/11/2012 e 01/06/2013 para as épocas de cultivo Inverno/Primavera e Verão/Outono, respectivamente. A colheita foi realizada nas primeiras horas da manhã, quando a umidade do ar ainda era alta e a temperatura era menor em relação a outros momentos do dia, conforme as recomendações de Kwiatkowski e Clemente (2007).

A produtividade foi submetida às análises de variância e regressão. As médias das épocas de cultivo foram analisadas pelo teste de Tukey a 5\%, e as lâminas irrigação a $5 \%$ de probabilidade pelo teste $\mathrm{t}$.

Para estimar o custo de produção, foi utilizado a estrutura de custo operacional total de produção, proposto pelo Instituto de Economia Agrícola - IEA detalhada em Martin et al. (1998). O custo operacional efetivo (COE), foi composto pelas despesas com insumos, serviços de mãos de obra e serviços mecânicos. Já o custo operacional total (COT) foi obtido por meio do COE acrescidos das despesas gerais, juros do custeio, manutenção do sistema de irrigação e depreciação do sistema de irrigação. Vários autores vêm aplicando a técnica de custo operacional total para análise econômica de resultados técnicos obtidos em experimentos como Kaneco et al. (2015) e Vilela et al. (2012).

Os custos foram obtidos com base nos seguintes itens: a) os gastos com insumos foram obtidos mediante o produto entre a quantidade dos materiais usados e os seus respectivos preços de mercado, no caso da energia elétrica, cada lâmina de irrigação teve o consumo de energia elétrica estimado conforme o proposto por Mendonça (2001), onde foi considerado o preço da tarifa Bandeira Verde, Grupo B2, com irrigação noturna fora do horário de ponta em período seco (ENERSUL, 2017). b) para as operações manuais, foi realizado um levantamento das necessidades de mão de obra nas diversas fases do ciclo produtivo do milho doce, relacionando, para cada operação, o número de homens/dia (HD) para executá-la e, em seguida, multiplicado o coeficiente técnico de mão de obra pelo valor médio da região; c) para outras despesas, foi considerada a taxa de $5 \%$ do total das despesas com o COE; d) a despesa com juros de custeio foi obtida considerando-se a taxa de 6,75\% e 5,50\% a.a. para época Inverno/Primavera (2012) e Verão/Outono (2013) respectivamente (taxa de juros utilizada em operações de crédito rural) 
sobre $50 \%$ do COE; e) a manutenção considerou-se $2 \%$ (do investimento inicial) do sistema de gotejamento, $7 \%$ para a fita gotejadora; e f) a depreciação do sistema de irrigação foi determinada pelo método linear, conforme apresentado por Vilas Boas et al. (2011).

O custo do sistema de irrigação por gotejamento foi realizado por meio da simulação de um projeto com área de um hectare, topografia plana e regular, utilizando água de boa qualidade para irrigação conforme o proposto por Vieira et al. (2011). Os preços para aquisição dos equipamentos foram consultados no comércio local.

Para a análise de lucratividade foram determinados os seguintes indicadores segundo Martin et al. (1998): a) Receita Bruta (RB), em R\$, determinada pela produção (em $\mathrm{Mg} \mathrm{ha}^{-1}$ de espigas) e o preço de venda em $\mathrm{R} \$ \mathrm{Mg}^{-1}$ : $\mathrm{RB}=$ produção $\mathrm{x}$ preço por unidade; b) Lucro Operacional (LO), em R\$, determinada pela diferença entre a RB e o COT: LO = RB-COT; c) Índice de Lucratividade (IL), em percentagem, determinado pela relação entre o LO e a RB: IL = (LO/RB) x 100; d) Preço de Equilíbrio (PE), em $\mathrm{R} \$ \mathrm{Mg}^{-1}$, determinado pela relação do COT com a produção, compreendido como o preço mínimo que garantiria o COT: PE = COT/produção; e) Produtividade de Equilíbrio (PRoE), em $\mathrm{Mg} \mathrm{ha}^{-1}$ de espigas, determinado pela relação do COT com o preço por unidade $\left(\mathrm{R} \$ \mathrm{Mg}^{-1}\right)$ compreendido como a produtividade mínima que garantiria o COT: $\mathrm{PRoE}=\mathrm{COT} /$ preço por unidade.

Os preços médios do milho verde foram obtidos por meios dos boletins mensais da Centrais de Abastecimento de Mato Grosso do Sul - CEASA-MS. Deste modo, os valores de venda do milho doce considerando na análise foi de $\mathrm{R} \$ 926,67 \mathrm{Mg}^{-1}$ para a época Inverno/Primavera e de $\mathrm{R} \$ 933,33 \mathrm{Mg}^{-1}$ para a época Verão/Outono (CEASA-MS, 2015), preço recebido pelo produtor.

\section{RESULTADO E DISCUSSÃO}

As variações dos elementos meteorológicos diários nos dois períodos de cultivo do milho doce estão apresentadas na Figura 1. 
Figura 1. Variação diária da temperatura do ar $\left({ }^{\circ} \mathrm{C}\right)$, umidade relativa do ar - UR (\%) e precipitação pluvial- PP (mm), nas épocas de cultivo: (A) Inverno/Primavera e (B) Verão/Outono. Chapadão do Sul - MS, 2012-2013

A.

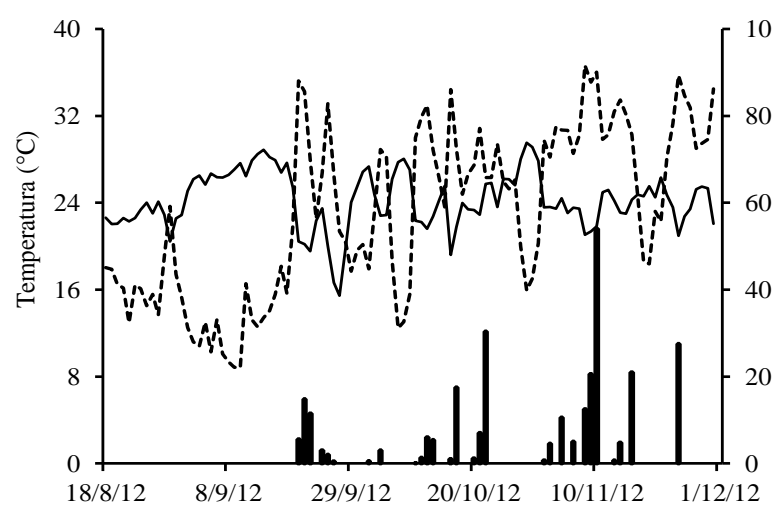

B.

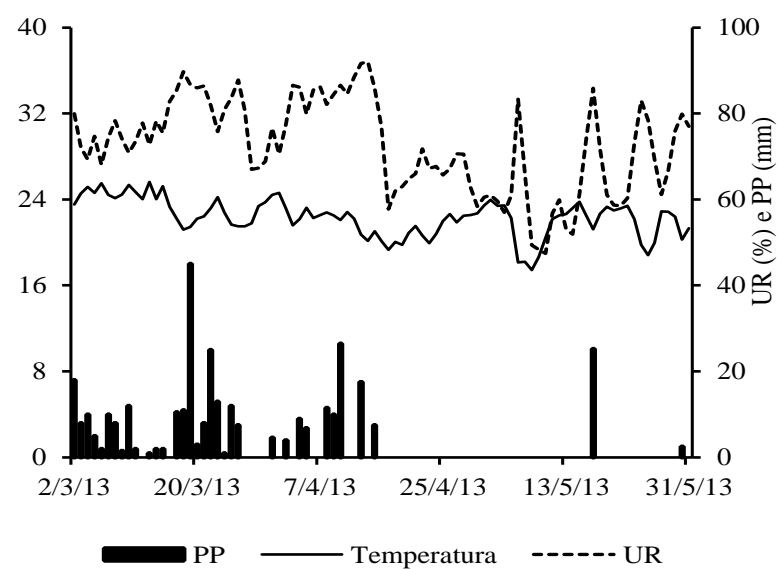

Fonte: Elaborado pelos Autores, 2020.

A temperatura média diária do ar foi maior na primeira época de cultivo (Inverno/Primavera), alcançando um valor médio de $24,2^{\circ} \mathrm{C}$, variando dentro de uma amplitude de 15,4 a $29,5^{\circ} \mathrm{C}$. Na segunda época de cultivo (Verão/Outono), o valor médio foi de $22,3^{\circ} \mathrm{C}$, oscilando entre 17,4 e $25,6^{\circ} \mathrm{C}$.

A ETo também foi maior no período de cultivo que abrangeu o Inverno/Primavera, alcançando um valor médio de 4,3 $\mathrm{mm} \mathrm{d}^{-1}$, variando dentro de uma amplitude de 1,5 a 6,5 $\mathrm{mm} \mathrm{d}^{-}$ ${ }^{1}$. No período Verão/Outono, o valor médio foi de $3,2 \mathrm{~mm} \mathrm{~d}^{-1}$, oscilando entre 1,8 e 5,3 $\mathrm{mm} \mathrm{d}^{-1}$.

No período Inverno/Primavera, as precipitações pluviais concentraram no final do ciclo do milho doce somando uma altura de $270,3 \mathrm{~mm}$, distribuídos em 23 eventos, com alturas variando de 2,6 a 54,0 $\mathrm{mm}$.

A produtividade de espigas de milho doce, apresentou um comportamento onde não foi possível ajustar o fator lâmina de irrigação com nenhum modelo polinomial de regressão, no entanto o fator épocas de cultivo conseguiu apresentar diferença significativas (Tabela 1).

Tabela 1. Resumo da análise de variância e valores médios da produtividade de espigas de milho doce irrigado, em função da época de cultivo e das lâminas de irrigação.

\begin{tabular}{lc}
\hline Tratamentos & Produtividade $\left(\mathrm{Mg} \mathrm{ha}^{-1)}\right.$ \\
\hline EP (Épocas de cultivo) & \\
Inverno/Primavera & $16,05 \mathrm{~B}$ \\
Verão/Outono & $17,64 \mathrm{~A}$ \\
\hline LI (Lâminas de Irrigação) & \\
$50 \%$ ETc & 16,76 \\
$75 \%$ ETc & 16,98 \\
$100 \%$ ETc & 17,06 \\
$125 \%$ ETc & 16,55 \\
\hline
\end{tabular}

(Continua) 
Tabela 1. Resumo da análise de variância e valores médios da produtividade de espigas de milho doce irrigado, em função da época de cultivo e das lâminas de irrigação.

\begin{tabular}{lc}
\hline Tratamentos & Produtividade $\left(\mathrm{Mg} \mathrm{ha}^{-1)}\right.$ \\
\hline LI & $0,18^{\text {ns }}$ \\
EP & $9,35^{* *}$ \\
LI x EP & $16,59^{* *}$ \\
DMS & $(1)$ \\
C.V. $(\%)$ & 1,07 \\
\hline
\end{tabular}

(Conclusão)

(1) Diferença mínima significativa; Médias seguidas de mesma letra nas colunas não diferem entre si pelo teste de Tukey $(\mathrm{p}<0,05) . * p<0,05 ; * * p<0,01 ;{ }^{\text {ns }} p>0,05$.

Esses resultados corroboram com Farinelli et al. (2003) avaliando 15 cultivares de milho comum em duas épocas em Jaboticabal-SP. Esses autores verificaram que o milho colhido no Verão apresentou, em média, valor 11,8\% superior ao colhido no Inverno. As produtividades de milho doce produzido nas duas épocas de cultivo estão dentro do intervalo observado por Carmo et al. (2012), para o mesmo hibrido. Ferreira et al. (2011), estudando lâminas de irrigação no milho doce também não conseguiu ajustar nenhum modelo polinomial de regressão. A Tabela 2 apresenta a interação entre os fatores lâminas de irrigação e época de cultivos.

Tabela 2. Desdobramento da interação lâminas de irrigação e épocas de cultivo para a produtividade de espigas de milho doce $\left(\mathrm{Mg} \mathrm{ha}^{-1}\right)$.

\begin{tabular}{ccc}
\hline Lâminas de & \multicolumn{2}{c}{ Épocas de cultivo } \\
\cline { 2 - 3 } irrigação & Inv. / Pri. ${ }^{(1)}$ & Ver. / Out. $^{(2)}$ \\
\hline $50 \%$ ETc & $14,00 \mathrm{~B}$ & $19,59 \mathrm{~A}$ \\
$75 \%$ ETc & $14,58 \mathrm{~B}$ & $19,37 \mathrm{~A}$ \\
$100 \%$ ETc & $17,55 \mathrm{~A}$ & $16,58 \mathrm{~B}$ \\
$125 \%$ ETc & $18,07 \mathrm{~A}$ & $15,03 \mathrm{~B}$ \\
\hline
\end{tabular}

${ }^{(1)}$ Inverno/Primavera. ${ }^{(2)}$ Verão/Outono. Médias seguidas de mesma letra nas linhas não diferem entre si pelo teste de Tukey $(p<0,05)$.

Na época de cultivo Inverno Primavera, as lâminas de 100\% e 125\% da ETc apresentaram produtividade superior aos da época Verão/Outono. Situação inversa ocorreu com as menores lâminas (50 e 75\% da ETc) onde as maiores produtividades ocorreram na época de cultivo Verão/Outono.

$\mathrm{Na}$ Tabela 3, encontra-se a estimativa do custo de operacional total (COT) obtido com a cultura do milho doce irrigado, com a lâmina de irrigação de $125 \% \mathrm{ETc}$, na época de cultivo Verão/Outono, no nordeste do Mato Grosso do Sul. Para os demais tratamentos foi utilizado uma estrutura similar para a determinação do COT, no entanto a Tabela 3 representa apenas um dos tratamentos avaliados. 
Tabela 3. Estimativa de custo de operacional total para um hectare, obtido com a cultura do milho doce irrigado na época Verão/Outono com uma lâmina de $125 \%$ da ETc.

\begin{tabular}{|c|c|c|c|c|c|}
\hline Componentes do custo & Especificação & Quant. ${ }^{(1)}$ & $\begin{array}{l}\text { Val. Uni. } \\
\text { (R\$) }\end{array}$ & $\begin{array}{c}\text { Val. Tot. }^{(3)} \\
\text { (R\$) }\end{array}$ & $\begin{array}{c}\text { Per. }{ }^{(4)} \\
(\%)\end{array}$ \\
\hline \multicolumn{6}{|l|}{ A- Insumos } \\
\hline Semente & Sc 60 mil sem. & 1,25 & 450,00 & 562,50 & 14,01 \\
\hline Calcário & $\mathrm{Mg}$ & 1,25 & 130,00 & 162,50 & 4,05 \\
\hline Adubo de semeadura & $\mathrm{Mg}$ & 0,60 & $1.282,00$ & 769,20 & 19,15 \\
\hline Herbicida & $\mathrm{L}$ & 4,00 & 14,01 & 56,04 & 1,40 \\
\hline Óleo mineral & $\mathrm{L}$ & 2,50 & 7,20 & 18,00 & 0,45 \\
\hline Adubo de cobertura & $\mathrm{Mg}$ & 0,13 & $1.350,00$ & 175,50 & 4,37 \\
\hline Adubo de cobertura & $\mathrm{Mg}$ & 0,40 & $1.212,00$ & 484,80 & 12,07 \\
\hline Inseticida $\mathrm{p} /$ semente & $\mathrm{L}$ & 0,30 & 99,00 & 29,70 & 0,74 \\
\hline Fungicida & $\mathrm{L}$ & 0,30 & 113,11 & 33,93 & 0,84 \\
\hline Energia elétrica & $\mathrm{kWh}$ & 489,33 & 0,12 & 58,18 & 1,45 \\
\hline Inseticida - Parte aérea & $\mathrm{L}$ & 0,25 & 94,95 & 23,74 & 0,59 \\
\hline Subtotal A & & & & $2.374,09$ & 59,12 \\
\hline \multicolumn{6}{|l|}{ B- Servicos mão de obra } \\
\hline Tratamento semente & $\mathrm{HD}^{(5)}$ & 0,05 & 70,00 & 3,50 & 0,09 \\
\hline Plantio/adubação & $\mathrm{HD}$ & 0,20 & 70,00 & 14,00 & 0,34 \\
\hline Vistoria da lavoura & $\mathrm{HD}$ & 0,70 & 70,00 & 49,00 & 1,19 \\
\hline Adubação cobertura & $\mathrm{HD}$ & 0,15 & 70,00 & 10,50 & 0,26 \\
\hline Aplicação inseticidas & $\mathrm{HD}$ & 0,10 & 70,00 & 7,00 & 0,17 \\
\hline Aplicação herbicida & HD & 0,10 & 70,00 & 7,00 & 0,17 \\
\hline Irrigação & $\mathrm{HD}$ & 7,84 & 70,00 & 548,62 & 13,38 \\
\hline Colheita & $\mathrm{HD}$ & 8,00 & 70,00 & 560,00 & 13,65 \\
\hline Subtotal B & & & & $1.199,62$ & 29,25 \\
\hline \multicolumn{6}{|l|}{ C-Serviços mecânicos } \\
\hline Aplicação de calcário & Hora máquina & 0,60 & 80,00 & 48,00 & 1,20 \\
\hline Aplicação fungicidas & Hora máquina & 0,60 & 80,00 & 48,00 & 1,20 \\
\hline Aplicação inseticidas & Hora máquina & 0,60 & 80,00 & 48,00 & 1,20 \\
\hline Plantio/adubação & Hora máquina & 1,00 & 80,00 & 80,00 & 1,99 \\
\hline Preparo do solo & Hora máquina & 2,00 & 80,00 & 160,00 & 3,98 \\
\hline Aplicação herbicida & Hora máquina & 0,60 & 80,00 & 48,00 & 1,20 \\
\hline Adubação cobertura & Hora máquina & 1,20 & 80,00 & 96,00 & 2,39 \\
\hline \multicolumn{4}{|c|}{ Subtotal C } & 528,00 & 13,15 \\
\hline \multicolumn{4}{|c|}{ D-Custo operacional efetivo (COE) } & $4.016,02$ & 85,99 \\
\hline \multicolumn{4}{|c|}{ E- Despesas gerais } & 200,80 & 4,30 \\
\hline \multicolumn{4}{|l|}{ F- Juros do custeio } & 110,44 & 2,36 \\
\hline \multicolumn{4}{|c|}{ G- Manutenção do sistema de irrigação } & 135,83 & 2,91 \\
\hline \multicolumn{4}{|c|}{ H- Depreciação do sistema de irrigação } & 207,32 & 4,44 \\
\hline \multicolumn{4}{|c|}{ I-Custo operacional total } & $4.670,41$ & 100,00 \\
\hline
\end{tabular}

Os gastos com insumos e serviços de mão de obra foram os mais elevados correspondendo $59,12 \%$ e $29,25 \%$ respectivamente. Dentro dos insumos, a adubação de base e a adubação de cobertura (ureia) foram os materiais que mais contribuíram nos gastos deste item, correspondendo a 19,15\% e 12,07\% respectivamente. Zure et al. (2011), estudando a viabilidade das adubações orgânica e química na produção do milho verde na região de Goiatuba-GO, 
verificou que a adubação de base e adubação de cobertura (nitrogênio) representa 22,93\% e $24,45 \%$ dos custos variáveis respectivamente.

Os custos que envolve o fator lâminas de irrigação (Energia elétrica e mão de obra para operação do sistema) na época de cultivo Inverno/ Primavera representaram 10,61\%, 15,12\%, 19,19\% e 22,89\% do COT para as lâminas de 50\%, 75\%, 100\% e 125\% da ETc respectivamente. $\mathrm{Na}$ época de cultivo Verão /Outono estes custos representaram 6,49\%, 9,43\%, 12,20\% e 14,49\% do COT para as lâminas de 50\%,75\%, 100\% e 125\% da ETc respectivamente.

Em ambas as épocas as lâminas de irrigação apresentaram receita crescentes obedecendo a tenência da produtividade (Tabela 4).

Tabela 4. Custo operacional total (COT) e receita bruta (RB) no cultivo do milho doce em função de diferentes lâminas de irrigação e épocas de cultivo.

\begin{tabular}{lcccc}
\hline \multirow{2}{*}{$\begin{array}{c}\text { Lâminas de } \\
\text { irrigação }\end{array}$} & \multicolumn{3}{c}{ COT $(\mathrm{R} \$)$} & \multicolumn{3}{c}{ Épocas de cultivo } \\
\cline { 2 - 5 } & Inverno/ Primavera & Verão/Outono & Inverno/ Primavera & Verão/Outono \\
\hline $50 \%$ ETc & $4.357,35$ & $4.370,07$ & $12.973,33$ & $18.284,00$ \\
$75 \%$ ETc & $4.570,39$ & $4.501,03$ & $13.510,80$ & $18.078,67$ \\
$100 \%$ ETc & $4.783,43$ & $4.631,98$ & $16.263,00$ & $15.474,67$ \\
$125 \%$ ETc & $4.996,47$ & $4.762,74$ & $16.744,87$ & $14.037,33$ \\
\hline
\end{tabular}

O milho doce cultivando na época Inverno/Primavera apresentou a maior receita bruta a reposição de água foi de $125 \%$ ETc (R\$ 16.744,87). Na Época Verão/Outono a receita bruta ocorreu com a lâmina de $50 \%$ da ETc (R\$18.284,00).

Observou-se lucro operacional em todos os tratamentos (Tabela 5), com destaque para a para época de cultivo Verão/Outono. Na época de cultivo Inverno/Primavera o maior lucro operacional ocorreu com a lâmina de $125 \%$ da ETc ( $\mathrm{R} \$ 11.869,93)$ e a menor ocorreu com a lâmina de 50\% da ETc (R\$ 8.694,83). O milho doce cultivado na época Verão/Outono obteve lucro operacional variando entre $\mathrm{R} \$ 9.366,92$ a $\mathrm{R} \$ 13.980,89$.

Tabela 5. Lucro operacional (LO) e índice de lucratividade (IL) do cultivo do milho doce em função de diferentes lâminas de irrigação e épocas de cultivo.

\begin{tabular}{lcccc}
\hline \multirow{2}{*}{$\begin{array}{c}\text { Lâminas de } \\
\text { irrigação }\end{array}$} & \multicolumn{3}{c}{ LO $(\mathrm{R} \$)$} & \multicolumn{3}{c}{ IL (\%) } \\
\cline { 2 - 5 } & Invernocas de cultivo & \\
\hline $50 \%$ ETc & $8.694,83$ & $13.980,89$ & 66,41 & 76,10 \\
$75 \%$ ETc & $9.033,49$ & $13.653,06$ & 66,17 & 75,10 \\
$100 \%$ ETc & $11.586,87$ & $10.926,57$ & 70,59 & 70,07 \\
$125 \%$ ETc & $11.869,93$ & $9.366,92$ & 70,16 & 66,07 \\
\hline
\end{tabular}

O índice de lucratividade, é um indicador que revela a proporção da receita bruta que se constitui em recursos disponíveis, após a cobertura do COT, apresentou positivos para todos os tratamentos (Tabela 5). 
Os preços da Megagrama (Mg) milho doce comercializado no CEASA-MS para os meses de novembro de 2012 e junho de 2013 foram de $\mathrm{R} \$$ 926,67 e $\mathrm{R} \$$ 933,33 respetivamente. Estes preços estão acima do preço mínimo (Tabela 6), necessário para garantir que o COT seja ressarcido.

Tabela 6. Preço de equilíbrio (PE) e produtividade de equilíbrio (PRoE) do milho doce em função de diferentes lâminas de irrigação e épocas de cultivo.

\begin{tabular}{lcccc}
\hline \multirow{2}{*}{$\begin{array}{c}\text { Lâminas de } \\
\text { irrigação }\end{array}$} & \multicolumn{3}{c}{$\mathrm{PE}\left(\mathrm{R} \$ \mathrm{Mg}^{-1}\right)$} & \multicolumn{3}{c}{ PRoE $\left(\mathrm{Mg} \mathrm{ha}^{-1}\right)$} \\
\cline { 2 - 5 } & Inverno/Primavera & Verão/Outono & Inverno/Primavera & Verão/Outono \\
\hline $50 \%$ ETc & 305,61 & 219,66 & 4,62 & 4,61 \\
$75 \%$ ETc & 307,09 & 228,48 & 4,83 & 4,74 \\
$100 \%$ ETc & 266,45 & 274,31 & 5,05 & 4,87 \\
$125 \%$ ETc & 269,78 & 310,53 & 5,26 & 5,00 \\
\hline
\end{tabular}

A produtividade mínima do milho doce comportou-se de forma similar ao preço mínimo (Tabela 6). A época de cultivo Inverno/ Primavera com a lâmina de $125 \%$ ETc foi a que apresentou a maior produtividade mínima. Este indicador revela qual a produtividade necessária para produzir uma receita bruta suficiente para pagar os gastos gerados pelo COT. Independente do tratamento a produtividade do milho doce no nordeste do Mato Grosso do Sul.

\section{CONCLUSÃO}

Todos os indicadores de lucratividades apontaram o milho doce irrigado com uma atividade agrícola viável.

O milho doce irrigado no nordeste do Mato Grosso do Sul, apresenta maior produtividade, quando cultivado na época Verão/Outono.

Os itens insumos e a mão de obra são os que apresentam maior participação do custo de produção milho doce.

\section{AGRADECIMENTOS}

À Syngenta Seeds, ao Grupo Feltre e a Fundação Chapadão.

\section{REFERÊNCIAS}


ALLEN, R. G.; PEREIRA, L. S.; RAES, D.; SMITH, M. Crop evapotranspiration: Guidelines for computing crop water requirements. Rome: FAO, 1998. 297 p. (Irrigation and Drainage Paper, 56).

ANA. Agência Nacional das Águas. Atlas da irrigação. Brasília: ANA, 2015. 86 p.

ARAUJO, E. F.; ARAUJO, R. F.; SOFIATTI, V.; SILVA, R. F. Qualidade fisiológica de sementes de milho-doce colhidas em diferentes épocas. Bragantia, Campinas, v. 65, n. 4, p. 687692, 2006.

BORIN, A. L. D. C.; LANA, R. M. Q.; PEREIRA, H. S. Absorção, acúmulo e exportação de macronutrientes no milho doce cultivado em condições de campo. Ciência e Agrotecnologia, Lavras, v. 34, Edição Especial, p. 1591-1597, 2010.

CARMO, M. S.; CRUZ, S. C. S.; SOUZA, E. J.; CAMPOS, L. F. C.; MACHADO, C. G. Doses e fontes de nitrogênio no desenvolvimento e produtividade da cultura de milho doce (Zea mays convar. saccharata var. rugosa). Bioscience Journal, Uberlândia, v. 28, sup. 1, p. 223-231, 2012.

CASTRO, M. A.; CUNHA, F. F.; LIMA, S. F.; PAIVA NETO, V. B.; LEITE, A. P.; MAGALHÃES, F. F.; CRUZ, G. H. M. Atributos físico-hídricos do solo ocupado com pastagem degradada e floresta nativa no Cerrado Sul-Mato-Grossense. Brazilian Geopraphical Journal, Ituiutaba, v. 3, n. 1, p. 498-512, 2012.

CENTRAIS DE ABASTECIMENTO DE MATO GROSSO DO SUL - CEASA -MS. Dados de origem dos produtos - Volume comercializado e Preço praticado. Disponível em < http://www.ceasa.ms.gov.br/ > Acesso em: 20 jan. 2015.

DOORENBOS, J.; KASSAM, A. H. Yields response to water. Rome: FAO, 1979. 306p. (FAO: Irrigation and Drainage Paper, 33).

EMPRESA ENERGÉTICA DE MATO GROSSO DO SUL S.A. - ENERSUL. Tarifas. Disponível em:<http://www.enersul.com.br/sua-conta/tarifas/>. Acesso em: 25 Jan. 2017.

FARINELLI, R.; PENARIOL, F. G.; BORDIN, L.; COICEV, L.; FORNASIERI FILHO, D. Desempenho agronômico de cultivares de milho nos períodos de safra e safrinha. Bragantia, Campinas, v. 62, n. 2, p. 235-241, 2003.

FERREIRA, M. G.; BRITO, M. E.; COSTA, F. B. D.; ARAÚJO FILHO, G. D. D.; ALVINO, F. C. Aspectos químicos e físicos dos grãos de milho doce sob estresse hídrico. Revista Brasileira de Agrotecnologia, Pombal, v. 1, n. 1, p. 1-6, 2011.

KANEKO, F. H.; SABUNDJIAN, M. T.; ARF, O.; FERREIRA, J. P.; GITTI, D. D. C.; NASCIMENTO, V.; LEAL, A. J. F. Análise econômica do milho em função da inoculação com azospirillum, fontes e doses de $\mathrm{N}$ em cerrado de baixa altitude. Revista Brasileira de Milho e Sorgo, v. 14, n. 1, p. 23-37, 2015.

KWIATKOWSKI, A; CLEMENTE, E. Características do milho doce (Zea mays L.) para industrialização. Revista Brasileira de Tecnologia Agroindustrial, Ponta Grossa, v. 1, n. 2, p. 93-103, 2007.

LIMA, S. F.; VENDRUSCOLO, E. P.; OLIVEIRA, T. R.; ANDRADE, M. G. O.; SIMON, C. A. Development and production of sweet corn applied with biostimulant as seed treatment.

Horticultura Brasileira, Recife, v. 38, n. 1; p. 94-100, 2020. 
MARTIN, N. B.; SERRA, R.; OLIVEIRA, M. D. M.; ANGELO, J. A.; OKAWA, H. Sistema integrado de custos agropecuários - CUSTAGRI. Informações Econômicas, São Paulo, v. 28, n. 1, p. 7-28, 1998.

MENDONÇA, F. C. Evolução dos custos e avaliação econômica de sistemas de irrigação utilizados na cafeicultura. In: Encontro Nacional de Irrigação da Cafeicultura no Cerrado, 6, 2001, Uberlândia. Anais[...] Uberlândia: UFU, 2001. 212p.

SANTOS, R. A.; DIVINCULA, J. S.; OLIVEIRA, K. R.; VENANCIO, L. P.; MISSIO, M. F.; FILGUEIRAS, R.; CUNHA, F. F.; ALEMAN, C. C. Remote sensing as a tool to determine biophysical parameters of irrigated seed corn crop. Semina: Ciências Agrárias, Londrina, v. 41, n. 2, p. 435-446, 2020.

SOUSA, D. M. G.; LOBATO, E. Cerrado: Correção do solo e adubação. 2.ed. Brasília: Embrapa Informação Tecnológica, 2004. 416 p.

SOUZA, E. J.; CUNHA, F. F.; MAGALHÃES, F. F.; SILVA, T. R.; SANTOS, O. F. Eficiência do uso da água pelo milho doce em diferentes lâminas de irrigação e adubação nitrogenada em cobertura. Revista Brasileira de Agricultura Irrigada, Fortaleza, v. 10, n. 4, p. 750-757, 2016.

VIEIRA, G. H. S.; MANTOVANI, E. C.; SOARES, A. A.; MONTES, D. R. P.; CUNHA, F. F. Custo da irrigação do cafeeiro em diferentes tipos de equipamento e tamanhos de área.

Engenharia na Agricultura, Viçosa, v. 19, n. 1, p. 53-61, 2011.

VILAS BOAS, R. C.; PEREIRA, G. M.; REIS, R. P.; LIMA JUNIOR, J. A.; CONSONI, R. Viabilidade econômica do uso do sistema de irrigação por gotejamento na cultura da cebola. Ciência e Agrotecnologia, Lavras, v. 35, n. 4, p. 781-788, 2011.

VILELA, R. G.; ARF, O.; GITTI, D. C.; KAPPES, C.; GOES, R. J.; DALBEM, E. A.; PORTUGAL, J. R. Manejo do milheto e doses de nitrogênio na cultura do milho em sistema de plantio direto. Revista Brasileira de Milho e Sorgo, v.11, p.234-242, 2012

ZÁRATE, N. A. H; VIEIRA, M. C; SOUZA, T. M; RAMOS, D. D. Produção e renda líquida de milho verde em função da época de amontoa. Semina: Ciências Agrárias, Londrina, v. 30, n. 1, p. $95-100,2009$.

ZUCARELI, C.; PANOFF, B.; PORTUGAL, G.; FONSECA, I. C. B. Doses e épocas de aplicação de nitrogênio em cobertura na qualidade fisiológica de sementes de milho doce.

Revista Brasileira de Sementes, Brasília, v. 34, n. 3, p. 480-487, 2012.

ZURE, G. E. O.; OLIVEIRA, V. M.; GOTARDO, M.; SANTOS, F. M. Produtividade de milho verde híbrido bm3061 sob diferentes tipos de adubação no plantio. Revista Verde de Agroecologia e Desenvolvimento Sustentável, Mossoró, v. 6, n. 2, p. 184-188, 2011. 